\title{
A ATIVIDADE LEGISLATIVA DO PODER EXECUTIVO: A INSTABILIDADE JURÍDICA COMO UM DE SEUS REFLEXOS $^{1}$
}

LEGISLATIVE ACTIVITY OF THE EXECUTIVE BRANCH: LEGAL INSTABILITY AS ONE OF ITS

REFLEXES

Arthur Simões BALDOCHI

Maria Rafaela Junqueira Bruno RODRIGUES ${ }^{3}$

ISSUE DOI: $10.21207 / 2675-0104.2019 .920$

\section{RESUMO}

Muito utilizado no Brasil é o fato do Poder Executivo ter a capacidade e legitimidade legiferante, razão desse fato, o objetivo geral do presente artigo é demonstrar os motivos e reflexos provenientes dessa atipicidade na Separação dos Poderes, que possibilita ao Poder Executivo legislar. O problema delimitou-se em buscar fontes históricas que justificam a atual necessidade das Constituições nas democracias ao redor do mundo, e autorizarem este compartilhamento de prerrogativas; em analisar a

\footnotetext{
${ }^{1} \mathrm{O}$ presente artigo sintetiza a monografia de conclusão da pesquisa, realizada para o Programa Interno de Bolsas de Iniciação Científica (PIBIC 2018-2019) da Faculdade de Direito de Franca (FDF), Franca/SP.

${ }^{2}$ Discente da Faculdade de Direito de Franca (FDF), Franca/SP. Bolsista do Programa Interno de Bolsas de Iniciação Científica (PIBIC 2018-2019).

${ }^{3}$ Graduação em Direito pela Faculdade de Direito de Franca (1991), Especialização em Metodologia do Ensino Superior (2001), Mestrado em Direito pela Universidade de Franca (2000), Especialização em Psicanálise Contemporânea (2006), Doutorado em Direito pela Universidade do Vale do Rio dos Sinos (2006), Pós Doutorado em Direito e Saúde na Università Degli Studi Di Messina - Itália (2014/2015), Aperfeiçoamento em Bioética Aplicada às Pesquisas em Seres Humanos (2013), Aperfeiçoamento em Educação para Jovens e Adultos pelo CEETEPS (2014) e Especialização em Gestão da Organização da Saúde Pública (UNIRIO/2014). Professora Universitária na Faculdade de Direito de Franca (2017) ministrando a Disciplina Direito Empresarial I.
} 
forma como se apresenta no sistema brasileiro e realmente se mantém efetivada e em respeito a tripartição de funções do Poder, petrificada na Constituição Federal vigorante no país. $\mathrm{O}$ atual trabalho de pesquisa se propôs à análise de dispositivos que permitem a atividade legiferante pelos detentores da prerrogativa Executiva, além das responsabilidades ou não que lhes incumbe no processo, além de terem sido apresentados os requisitos para a adoção de tal instituto, bem como dos reflexos positivos e negativos. Ao analisar o instituto, foi possível verificar as distinções entre modelos adotados no direito estrangeiro e a forma como é procedido no Brasil através das Medidas Provisórias. Também tornou possível, questionar-se acerca da responsabilidade dos representantes frente à Constituição, diante dessa prerrogativa de legislar em casos extraordinários, de maneira a sugerir que se possa utilizar o instituto de forma correta e respeitosa ao princípio que lhe originou, consagrado por Montesquieu. No entanto, em momento algum se teve por pretensão esgotar-se a temática, mas sim ampliar os espaços de discussão.

Palavras-chave: Poder Executivo. Poder Legislativo. Medidas Provisórias. Tripartição de Funções do Poder. Processo Legislativo.

\begin{abstract}
The general objective of this article is to estabilish the motives and reflections arising from an atypicality in the Separation of Powers, enabling the Executive Power to legislate. The problem was summarized in seeking historical sources that justify the current necessity of the Constitutions of the democracies around the world allowing this sharing of prerogatives, in addition to analyzing whether the way it is done in the Brazilian system is really effective and respects the division of functions of each Power in their form and assignments or not. The current monographic work propounds the analysis of the devices that allow the legifferant activity by the holders of the Executive prerogative, additional to their responsibilities or not, the process and the requirements for the adoption of such institute, as well as the positive and negative reflections. When analyzing the institute, it was possible to verify the distinctions between the models adopted in foreign law and the one that is in proceeded in Brazil thought the provisional measures, besides raising the questioning about the responsibility of the representatives with to the constitutional requirements, so that it may be the prerogative to legislate in extraordinary cases that, have been used in a correct and respectful manner to the enshrined principle by Montesquieu.
\end{abstract}

Keywords: Executive Power. Legislative Power. Provisional Measures. Separation of Powers. Legislative Process.

\title{
INTRODUÇÃO
}

A capacidade legiferante atribuída ao Poder Executivo, fruto das permissões constitucionais legislativas, têm suscitado discussões intermináveis a respeito de sua real legitimidade frente ao Princípio petrificado de Tripartição dos Poderes do Estado, que quer ser reconhecido como democrático e de direito.

Nessa seara, a escolha do presente tema justificou-se pela grande controvérsia existente nas constantes contestações acerca da Separação dos Poderes, para demonstrar estar assegurada ou não, frente aos corriqueiros abusos do Poder Executivo na utilização de prerrogativas atípicas a sua função. 
Inquestionável, porém, a importância de um Poder Legislativo dinâmico, célere e que atenda aos anseios e demandas da população, principalmente quando se trata de questões de caráter de urgência, que demandam uma rápida atuação dos representantes imbuídos de poderes públicos.

Sabe-se, contudo, que a atuação do Legislativo no Brasil é limitada por diversos entraves burocráticos, coalizões forçadas, além do moroso Processo Legislativo, o que acaba por dificultar e diminuir e capacidade de rápida atuação em situações que dependem de atos Legislativos.

Assim, com o escopo de sanar esta problemática, a legislação possibilitou haver uma exceção ao Princípio Tripartite de Funções dos Poderes, criada em diversas democracias, permitindo ao Chefe do Executivo agir, em caráter legiferante, mediante situações de urgência e relevância.

No Brasil, muito influenciado pelo modelo Italiano, foi consagrado na Constituição de 1988 o instituto das Medidas Provisórias.

O tema em discussão tratou do assunto cada vez mais presente em discussões políticas e em questionamentos de como otimizar o moroso Processo Legislativo brasileiro, para que possa ser descaracterizada a utilização frequente da Medida Provisória por parte do Poder Executivo, em respeito à Tripartição de Funções do Poder.

Para debater toda a questão, o texto se apresenta em três capítulos, sendo o primeiro uma recapitulação histórica, de como surgiu a ideia de que o Estado deveria organizar-se em três diferentes sortes de Poderes, ou funções, para que uma divisão fosse independente da outra, evitando a concentração do Poder em um só governante, dificultando o surgimento de um possível autoritarismo alimentado pela concentração de poder.

No segundo capítulo, contextualizou-se os institutos próximos das Medidas Provisórias no direito estrangeiro, tanto em países parlamentaristas, quanto em democracias cujo sistema é presidencialista, para fim de comparação da funcionalidade e impactos diversos que pode ocorrer frente à sua utilização e, portanto, caso venha a ser. Por fim, se verificará a fundo como funcionam as Medidas Provisórias dentro do Processo Legislativo brasileiro, bem como analisou-se sua atual situação de abuso, além dos impactos no mundo jurídico provenientes de tal prática.

A metodologia empregada para se atingir aos fins objetivados pela pesquisa foi a pesquisa teórica, baseada nos métodos dedutivo- 
bibliográfico e comparativo, em consulta a doutrinas, jurisprudências, artigos e demais meios virtuais.

Desta forma, busca-se entender a necessidade da existência de um instituto que conceda a prerrogativa legiferante ao Poder Executivo, bem como analisar a forma como vem sendo utilizada, além dos impactos e efeitos que derivam de tal.

No entanto, cabe ressaltar que a presente pesquisa não teve por fim esgotar a temática, mas apresentar um viés quanto aos seus principais aspectos, para que se possa ampliar os espações de discussão acadêmica, vislumbrando a melhoria dos institutos envolvidos.

\section{PRINCÍPIO DA SEPARAÇÃO DOS PODERES E SEUS ANTECEDENTES}

Com a grande crescente da classe burguesa no século XVIII, marcada pelo período das grandes navegações e da conquista de novos mercados, culminou por emergir uma grande concentração de riqueza pela burguesia, assim como a consequente concentração de poder e influência.

Considerando que a concentração de Poderes nas mãos de um só governante atrapalhava a "decolagem" da classe burguesa, fomentou-se junto ao efervescente pensamento filosófico do momento, o nascimento de um movimento denominado "Iluminismo".

Tal corrente, a iluminista, levou à classe burguesa a possibilidade de imaginar um contexto onde as liberdades civis não seriam limitadas pela vontade de uma pessoa com poderes concentrados em suas mãos, de forma que a possibilitaria de prosperar cada vez mais. Defendiam um Estado Constitucional eivado por uma autoridade com poderes definidos. O maior expoente dentre este contexto foi John Locke, o britânico que fazia oposição ao regime absolutista vigente à época, sendo considerado por muitos, o pai do liberalismo político.

Assim, John Locke em "O Segundo Tratado Sobre o Governo Civil”, percebera e enumerara três formas distintas de Poder, sendo eles: o Legislativo, Executivo e o Federativo. ${ }^{5}$

\footnotetext{
${ }^{4}$ O Iluminismo foi um movimento intelectual, surgido no século XVIII na Europa. Suas diretrizes fundamentais defendiam o uso da razão, além de pregar maiores liberdades individuais, econômicas e políticas.

${ }^{5}$ LOCKE, John. Dois Tratados Sobre o Governo. Martins Fontes: São Paulo, 1998 (traduzido por Julio Fischer). Tratam-se de duas obras filosóficas políticas publicadas de forma anônima por John Locke,
} 
$\mathrm{Na}$ concepção de Locke, era o Poder Legislativo uma função suprema, cabendo-lhe governar através de leis estabelecidas e promulgadas, sem variações particulares e operando da mesma forma para ricos e para os pobres. Era intransferível e irrenunciável a função de elaborar as leis, sendo, então, a instituição legislativa a primeira lei positivada e fundamental de todos os Estados. ${ }^{6}$

O legislativo, segundo a concepção de Locke, estava investido de um poder supremo, era a própria alma do corpo político, porque representava o consenso social. ${ }^{7}$ Vê-se que, desde Locke, situado historicamente em meio à Revolução Gloriosa (1688-1689), que culminara na assinatura do Bill Of Rights, ferramenta limitadora de soberanos, já se pressentia o quão fundamental e necessária era a um Estado, para que fosse organizado, uma derivação do Poder que cumprisse com suas funções de editar leis com a finalidade de atingir-se uma certa segurança quanto aos direitos e deveres inerentes a cada cidadão. ${ }^{8}$

Já o Poder Executivo, conforme Locke, se responsabilizaria pela execução das leis internamente junto à sociedade, providenciando medidas para que fossem as determinações previstas nas leis editadas cumpridas dentro dos limites territoriais que resguardavam este Poder. Assim, estaria o Executivo subordinado, de certa forma, ao Legislativo, por sua função depender da movimentação na edição de leis.

O terceiro Poder previsto por Locke era o chamado de Federativo, cuja função era inerente a realizar alianças exteriores ao território em que imperava, buscando firmar tratados comerciais, declarar guerra ou buscar a paz. Nota-se que este poder era associado, de certa forma, e diretamente ao executivo, por ter sua atuação ocorrência junto à movimentação da execução das leis já determinadas pelo legislativo.

Porém, só na obra "Do Espírito das Leis", em 1748, de CharlesLouis de Secondat, o barão de La Brède e de Montesquieu, é que se consolida a técnica mais aceita e com mais prestígio em toda a idade liberal, para a separação dos poderes. Para que não se possa abusar do Poder, fazse mister organizar a sociedade política de tal forma que o poder seja um freio ao poder, limitando o poder pelo próprio poder. ${ }^{9}$

em 1681. O Primeiro Tratado, cuida de refutar ideias de Robert Filmer, defensor do patriarcalismo, enquanto o Segundo Tratado traça uma teoria de sociedade política civil, a partir do direito natural e da ideia do contrato social.

${ }^{6}$ Ibidem.

${ }^{7}$ COSTA, Nelson Nery. Ciência Política, 2a ed., Editora Forense: Rio de Janeiro, 2006, p. 114.

${ }^{8}$ Ibidem.

${ }^{9}$ MONTESQUIEU. Do Espírito das Leis. Martins Fontes: São Paulo, 2000, p. 407. 
O "Barão" de Montesquieu não foi o criador da doutrina, mas foi o idealizador que a deu os mais precisos contornos e retoques. Desta forma, rememora André Ramos Tavares que a ideia que prevaleceu foi a de que a Separação dos Poderes, como doutrina política, teve sua origem na obra de Montesquieu. ${ }^{10}$ De sua autonomia, foi a atribuição à "Função Judicial" o caráter pleno independente.

Mesmo que não tenha sido o autor propriamente dito deste preceito científico-político, resguarda-se a ele o mérito de ter exposto e recomendado de forma eficaz a toda sociedade.

$\mathrm{O}$ fato de o princípio circundar o conceito de liberdade é de certa forma, a maior reflexão do ponto de vista político, trazido na obra de Montesquieu. O ponto é: o autor conceitua que a liberdade é o direito de poder fazer tudo o que permitem as leis, de forma que, em casos de governos com tanto o Poder de criar a lei, quanto o de executá-las, consequentemente resultaria em uma tendência de "abusar" do mesmo, tendo em vista a "carta branca" que o conceito de liberdade os daria. Sabese, porém, que o abuso tende a avançar até o ponto em que se deparem seus limites, e extrai-se daí a motivação do autor, deparando-se com a necessidade de organizar a sociedade de modo que uma divisão do poder seja o limite estabelecido ao outro.

Neste espeque, Montesquieu distingue que em cada concentração de Poder ou existência de Estado, existem três sortes de poderes: aquele poder das coisas que dependem do direito das gentes, o Executivo, conforme seus dizeres - encarregando ao príncipe os deveres de guerra e paz, poder das coisas eu dependem do direito civil - Judiciário - dando a faculdade ao magistrado de punir e julgar crimes e dissídios, e o poder de formular normas e aperfeiçoá-las (Legislativo).

Desta técnica de separação, aduz Montesquieu que a liberdade política seria um reflexo do contraponto que cada forma segregada de Poder faria reciprocamente uma à outra. Deste modo, realçou que um grande benefício abarcado por sua teoria é a segurança à liberdade individual, de forma que, em cada um dos poderes por suas atribuições, assegura-se ao cidadão a sua liberdade pela certeza do direito que regula suas relações sociais e também pela garantia de que os atos provenientes de órgãos de Estado, serão contidos a partir das limitações das normas jurídicas pré-constituídas afim de delegar a um poder, a capacidade de contrapor ao outro, porém com uma finalidade comum.

${ }^{10}$ TAVARES, André Ramos. Curso de direito constitucional positivo, Editora Saraiva: São Paulo, 2006 , p. 859. 


\subsection{O SISTEMA DE FREIOS E CONTRAPESOS}

O poder estando distribuído entre as três distintas funções já elencadas, e exercido pelos órgãos estatais competentes e dotados de autonomia e independência, é tido pelos partidários do liberalismo político como garantia de equilíbrio político que evita ou, pelo menos, minimiza os riscos de abuso de poder. O Estado que estabelece a separação dos poderes evita o despotismo e assume feições liberais. ${ }^{11}$

Este objetivo de liberdade política é perseguido de duas formas: primeiramente, impõem-se a colaboração e consenso dos operadores dos órgãos estatais nas tomadas de decisões, e, em segundo lugar, porém, não menos importante, estabelecendo e consolidando mecanismos e formas de fiscalização e contenção recíproca dos poderes e funções estatais, sendo denominado tal sistema de "freios e contrapesos" - checks and balances.

Dentro deste sistema, consagrado por Montesquieu, a norma estabelecida é de que o Poder deve ser limitado pelo próprio Poder. Seguindo esta máxima, a Constituição Federal brasileira estabeleceu diversas formas diferentes de aplicar tal princípio e evitar abusos de poder.

Destaca-se, por exemplo, no art. $5^{\circ}, \mathrm{XXXV}^{12}$, o qual possibilita o Poder Judiciário de rever atos de determinada CPI - competência do Legislativo - que extrapole o postulado da reserva constitucional de jurisdição, invadindo a competência do próprio judiciário. No art. $101^{13}$, o seu parágrafo único (c/c o art. 52, III, “a”, e o art. 84, XIV), preceitua que os Ministros do STF - Judiciário - serão nomeados pelo Presidente da República - Executivo -, e depois a escolha passará ao crivo da maioria absoluta do Senado Federal - Legislativo.

Além do mais, pelo equilíbrio buscado ao se adotar o sistema de freios e contrapesos, são concedidas a cada divisão do poder, funções atípicas à sua de origem, tendo o legislativo, muitas vezes, funções executivas (dispor sobre sua organização, provendo cargos, concedendo férias e etc.) e jurisdicionais (julgar crimes de responsabilidades do executivo); e o executivo, funções legislativas (editar decretos e atos

\footnotetext{
${ }^{11}$ LENZA, Pedro. Direito Constitucional Esquematizado. Saraiva: São Paulo, 2016, p. 595.

12 Art. $5^{\circ}$. Todos são iguais perante a lei, sem distinção de qualquer natureza, garantindo-se aos brasileiros e aos estrangeiros residentes no País a inviolabilidade do direito à vida, à liberdade, À igualdade, à segurança e à propriedade, nos termos seguintes: XXXV - a lei não excluirá da apreciação do Poder Judiciário lesão ou ameaça a direito. (Constituição Federal do Brasil).

13 Art. 101. Parágrafo único: Os Ministros do Supremo Tribunal Federal serão nomeados pelo Presidente da República, depois de aprovada a escolha pela maioria absoluta do Senado Federal. (Constituição Federal do Brasil).
} 
provisórios) e jurisdicionais (julgar e apreciar defesas e recursos administrativos); e o judiciário, com natureza atípica legislativa (redigir o regimento interno de seus tribunais) e executiva (administrar sua estrutura interna, conceder férias aos seus serventuário).

\subsection{O PODER EXECUTIVO E SUAS FUNÇÕES ATÍPICAS}

No presidencialismo brasileiro, uma herança da criação estadunidense confere ao Presidente da República ampla liberdade para a escolha de Ministros de Estados, além de poder destitui-los do cargo de maneira ad nutum. Além disso, tem-se que a escolha dos magistrados que compõem a mais alta corte do judiciário, é uma indicação política.

Tal premissa, garantida no art. 84, inciso XIV da Constituição Federal, acaba por criar, de maneira ou de outra, um vínculo entre o Presidente e o Ministro indicado. Vínculo este que pode ferir de forma fatal a independência ou imparcialidade, que é requisito fundamental democrático inerente a todo magistrado na hora de julgar ou decidir eventualmente em alguma Ação na Corte que possa impactar alguma pretensão política ou administrativa do Presidente da República.

No tocante ao Legislativo, verifica-se a possibilidade de uma enorme ingerência do Poder Executivo, ao analisar-se sua capacidade legiferante, através de Decretos Presidenciais e Medidas Provisórias.

Conforme o resguardado pelo artigo 62 da Constituição Federal, o Presidente da República pode adotar, em casos de relevância e urgência, medida provisória com força de lei, sendo submetidas de imediato ao Congresso Nacional e entrando em vigência na data de sua edição.

Essa prerrogativa é exclusiva àquele que exercita o cargo de chefia do Poder Executivo, podendo tomar uma decisão que, no momento de sua edição, passa a ter a força de uma lei, criando ou extinguindo relações jurídicas. Ao ser legiferada, dois básicos efeitos são observados: inova a ordem jurídica imediatamente, e provoca o Congresso Nacional a deliberar sobre o assunto. ${ }^{14}$

Em resumo, as medidas provisórias são atos normativos primários, sob condição resolutiva, de caráter excepcional no quadro da

\footnotetext{
${ }^{14}$ MENDES, Gilmar Ferreira; COELHO, Inocêncio Mártires; BRANCO, Paulo Gustavo Gonet. Curso de Direito Constitucional, 6ª Ed., São Paulo: Saraiva, 2011, p. 838.
} 
separação dos Poderes, e, no âmbito federal, apenas o Presidente da República conta o poder de editá-las. Ostentam nítida feição cautelar. Embora produzam o efeito de concitar o Congresso a deliberar sobre a necessidade de converter em norma certo trecho da realidade social, não se confunde, com meros projetos de lei, uma vez que desde quando editadas já produzem efeitos de norma vinculante. ${ }^{15}$

\section{ATIVIDADE LEGISLATIVA DO PODER EXECUTIVO NO DIREITO ESTRANGEIRO}

\subsection{NO DIREITO ITALIANO}

Os constituintes italianos, em 1947, tinham a missão de suceder três regimes, sendo dois totalitários, que seu país havia suportado, sendo eles: Estatuto Albertino (vigorou de 1848 até 1922 sob o reinado de CarlosAlberto) o fascismo de Mussolini (1922-1943) e o período transitório pósfascismo, em que houveram duas Constituições provisórias (1943-1947). Assim, existia uma grande preocupação em afastar definitivamente a preponderância do executivo sob o parlamento, criando mecanismos capazes de garantir o Estado de Direito e de contrapesos dos poderes, como a criação da Corte Constitucional, o referendo popular a as regiões autônomas.

Entretanto, após longos debates deliberou-se nas Assembleias Constituintes acerca do caráter legiferante do Poder Executivo, prevaleceu a tese de que seria disponibilizado ao Governo, formado por parlamentares, e não ao Presidente da República, a prerrogativa de legislar em casos de urgência.

Assim, a Costituzione della Repubblica Italiana, promulgada no dia 22 de dezembro de 1947 pela Assembleia Constituinte, tem disposto em seu artigo 77 o seguinte:

O Governo não pode, sem delegação das Câmaras, expedir decretos que tenha valor de lei ordinária. Quando em casos extraordinários de necessidade e urgência, o Governo adotar, sob sua responsabilidade, providências provisórias com força de lei, deverá apresenta-las no mesmo dia, para conversão, às Câmaras que,

\footnotetext{
${ }^{15}$ Ibidem.
} 
mesmo se dissolvidas, serão imediatamente convocadas e devem reunir-se em cinco dias. Os decretos perdem a eficácia desde o início se não forem convertidos em lei dentro de sessenta dias a partir de sua publicação. As Câmaras podem, entretanto, regular por lei as relações jurídicas decorrentes dos decretos não convertidos. ${ }^{16}$

Deve-se observar, porém, que a prerrogativa legiferante do Governo no parlamentarismo italiano, justifica-se, pois, o Parlamento controla o Governo, votando a lei e o orçamento provenientes do decreto, caso em que se reprovada, implica na imediata dissolução do Governo, através de uma moção de desconfiança. Vê-se que o constituinte italiano soube estruturar um sistema que possibilita a utilização da prerrogativa de urgência, porém ao mesmo tempo adverte o Governo em casos de abuso do mesmo.

A respeito das regras e pressupostos para que possa o governo (que representa o Poder Executivo) editar o decreto com força de lei, são elas os requisitos de necessidade e urgência. Os requisitos serão apreciados imediatamente após a edição do decreto, afim de verificar se o mesmo está em consonância com os ditames da Carta Magna.

\subsection{NO DIREITO ESPANHOL}

Nos mesmos parâmetros do Decreto-lei italiano, a Constituição Espanhola a partir de seu art. 86, confere ao Governo a prerrogativa legiferante sob a figura dos decretos-leyes, na mesma forma, em situações de "extraordinária e urgente necessidade". Assim, é resguardado ao Governo espanhol a possibilidade de editar matéria legislativa, devendo submetê-las de imediato ao parlamento (Cortes Generales). Veja-se:

Artículo 86: Em caso de extraordinária y urgente necesidad, el Gobierno podrá dictar disposiciones legislativas provisionales que tomarán la forma de Decretos-leys y que no podrán afectar al ordenamento de las instituiciones básicas del Estado, a los derechos, deberes y libertades de los ciudadanos regulados em el

${ }^{16}$ SAMPAIO, Marco Aurélio. A Medida Provisória no Presidencialismo Brasileiro, $1^{\text {a }}$ Ed., São Paulo: Malheiros, 2007, p. 40. 
Título I, al régimen de las Comunidadess Autónomas ni al Derecho electoral general. ${ }^{1718}$

O constituinte, admitindo a inclusão do instituto pela Constituição, tratou com a cautela necessária dispondo um extenso rol de restrições e vedações, incluindo à básica estruturação das instituições do Estado, dos direitos e deveres, das liberdades e dos regimes das Comunidades Autônomas, além do Direito Eleitoral.

O modelo parlamentarista vigente na Espanha, tem uma notada diferença com relação ao formato italiano, que faz com que a figura do Rei não sobressaia as funções parlamentares. Ocorre que, havendo uma decisão favorável para o fim de ratificar o decreto-lei, a conversão do mesmo em lei não é o efeito que se impera, ou seja, sua natureza jurídica permanece a de um decreto-lei e não o de uma lei.

\section{A SISTEMÁTICA DA MEDIDA PROVISÓRIA NO BRASIL: CAUSAS, MEIOS E REFLEXOS.}

$\mathrm{Na}$ Assembleia Constituinte de 1988, talhou-se a partir do modelo dos decretos-lei italianos as Medidas Provisórias, tais como conhecidas atualmente.

Ocorre que, observando registros da Assembleia Nacional Constituinte, verifica-se que havia uma grande crença por parte dos constituintes de que o Sistema de Governo que seria adotado no país, era o Parlamentarismo, assim como na Itália, detentora da Carta Constitucional que mais influenciou na Constituição de 1988.

Neste sentido, destacou Brasiliano Pereira dos Santos

O certo é que, após numerosos debates, na dúvida, os constituintes deixaram, no projeto de constituição, a Medida Provisória, por que todos acreditavam, ou faziam acreditar, que, conforme tudo estava

17

Disponível

em: <www.tribunalconstitucional.es/es/tribunal/normativa/Normativa/CEportugu\%C3\%A9s.pdf >.

Acesso em: 29 jul. 2019.

18 Tradução: “Artigo 86: No caso de necessidade extraordinária e urgente, poderá o Governo emitir disposições legislativas provisórias, que assumirão a forma de decretos-lei e que não poderão afetar o ordenamento das instituições básicas do Estado, os direitos, deveres e liberdades dos cidadãos regulamentados no Título I, nem do Regime das Comunidades Autônomas ou do Direito Eleitoral em geral. 
a indicar, seria realmente implantado o parlamentarismo entre nós. ${ }^{19}$

Em meio aos debates na Assembleia Nacional Constituinte, o relator Bernardo Cabral teve posicionamento decisivo no convencimento de que não seria nada extraordinário que o Presidente da República pudesse editar medidas com força de lei, e pode-se extrair das palavras do relator, que era mesmo o Sistema Parlamentarista que supunha estar vigendo, assim disse o parlamentar: ${ }^{20}$

A quem essas medidas serão submetidas, de imediato, para poderem ser convertidas em lei? (...). Ao Congresso Nacional. Para que e porque ao Congresso Nacional? Por que o Congresso Nacional é o que será o órgão competente, tanto assim que, se ele estiver em recesso, diz o dispositivo que ele será convocado extraordinariamente para se reunir. O que e se está fazendo aqui é aquilo que se fez nos países adiantados recentemente. Por exemplo, na Bélgica, essa medida é chamada arretê du roi; na França, (...) é ordanance, na Inglaterra são as mensagens com o encaminhamento de diploma legal ao parlamento; e na Itália, como ressaltou o constituinte Nelson Jobim, decretos com força de lei. ${ }^{21}$

Desta feita, os constituintes sentiram a necessidade de dar ao Presidente d República a prerrogativa de edição de Medidas Provisórias com força de lei, com a finalidade de atender situações urgentes e relevantes, porém, resguardando ao Legislativo um posicionamento mais atuante. Inclusive, porque, tais situações apresentam e mantém um subjetivismo que se lhe apresenta como peculiar, devendo os demais Poderes se acautelarem no que diz respeito a não permitirem abusos decorrentes de sua má utilização.

A Constituição Federal de 1988 dispõe em seu art. 62 que, em casos de relevância e urgência, pode o Presidente da República adotar Medidas Provisórias com força de lei, tendo de submetê-las de imediato ao Congresso Nacional. Editada a Medida Provisória, esta permanecerá em vigor pelo prazo de 60 dias (prorrogáveis por igual período), sendo submetida ao Poder Legislativo para sua apreciação, conforme termos dos doze parágrafos do art. 62, incluídos pela $\mathrm{EC} \mathrm{n}^{\circ} 32 / 01$, disciplinadores do processo legislativo extraordinário das Medidas Provisórias.

\footnotetext{
${ }^{19}$ SANTOS, Brasiliano Pereira dos. As Medidas Provisórias no Direito Comparado e no Brasil, $1^{\text {a }}$ Ed., São Paulo: LTR, 1994, p. 286.

${ }^{20}$ SUZUKI, Anderson; DIAS, Fábio Marques; VIOLIN, Marco Antônio. Medidas Provisórias e Segurança Jurídica, $1^{\text {a }}$ Ed., São Paulo: Juarez de Oliveira, 2003, p. 17.

${ }^{21}$ Ibidem.
} 
Estabelece a Resolução ${ }^{\circ} 1$, de 8 de maio de 2002, que nas 48 horas que subseguirem à publicação da Medida Provisória no Diário Oficial da União, a Presidência da Mesa do Congresso Nacional, se encarregará de publicar e distribuir avulsos da matéria e designará Comissão Mista para emitir parecer sobre ela. ${ }^{22}$ Será montada uma comissão mista integrada por 12 deputados e senadores, com igual número de suplentes, todos indicados pelos respectivos líderes das bancadas, sendo obedecida a proporcionalidade dos partidos ou blocos parlamentares nas Casas Legislativas. Terá esta Comissão Mista, o improrrogável prazo de 14 dias contados da publicação da Medida Provisória no DOU (Diário Oficial da União) para que emita parecer único, manifestando sobre a matéria em itens apartados, quanto aos aspectos constitucional e sobre os requisitos de relevância e urgência, além da adequação financeira e orçamentária. ${ }^{23}$ Assim, o parecer da Comissão Mista será encaminhado ao Plenário da Câmara dos Deputados, para, assim que aprovado, a Medida Provisória será encaminhada ao Senado Federal, para igual discussão e votação.

Importante ressaltar que, caso a Medida Provisória não seja apreciada em até 45 dias contados de sua publicação, esta entra em regime de urgência, porém permanecendo ainda com força de lei. A Emenda Constitucional $n^{\circ} 32 / 01$ criou uma espécie nova de regime de urgência constitucional para as Medidas Provisórias, no qual teriam ambas as Casas Legislativas o exíguo prazo de 15 dias, para apreciarem o inteiro teor do ato provisório. Este regime de urgência constitucional, sobrestará todas as demais deliberações a serem analisadas nas Casas Legislativas, até que seja apreciado o texto da Medida Provisória. É o conhecido "trancamento de pauta".

Em inédita decisão, o então Presidente da Câmara dos Deputados, Michel Temer, entendeu que o sobrestamento das deliberações legislativas $\left(\$ 6^{\circ}\right.$, art. 62$)$, somente se aplica aos projetos de lei ordinária ${ }^{24}$. Foi esse entendimento posteriormente corroborado por decisão do Supremo Tribunal Federal, através do Ministro Celso de Mello, negando liminar em medida cautelar de mandado de segurança ajuizado por alguns membros do Congresso Nacional. Sua decisão foi referendada pelo plenário da Suprema Corte.

\footnotetext{
${ }^{22}$ MORAES, Alexandre de. Direito Constitucional, 33ª Ed., São Paulo: Atlas, 2017, p. 492.

${ }^{23}$ Ibidem.

${ }^{24}$ Ibidem, p. 493.
} 
Sendo a Medida Provisória aprovada sem alterações, será convertida em lei, sendo seu texto promulgado pela Mesa do Congresso Nacional, que conforme art. 57, $\S 5^{\circ}$ da Carta Magna de 1988, a Mesa do Congresso é presidida pelo Presidente do Senado, então por ele, será a lei promulgada.

Existe, também, a possibilidade de serem as Medidas Provisórias alteradas, através da apresentação de emendas pelos parlamentares. Porém, para que sejam admitidas essas emendas, deve observar-se a pertinência temática, ou seja, são vedadas as emendas que versem sobre matéria estranha aquela tratada na Medida Provisória. Caso a comissão mista apresente parecer pela aprovação da Medida Provisória, porém com emendas, deverá também apresentar projeto de lei de conversão, bem como o projeto de decreto legislativo, com a finalidade de regulamentar-se as relações jurídicas decorrentes da vigência dos textos suprimidos ou alterados. ${ }^{25}$

Caso ocorra a rejeição tácita, que é a não apreciação da Medida Provisória pelo Congresso Nacional após os 120 dias (60 prorrogados por mais 60), a medida perderá sua eficácia desde a data de sua edição, operando efeitos ex tunc, restando ao Congresso disciplinar as relações jurídicas decorrentes da rejeição tácita através de decreto legislativo (art. $62, \S \S 3^{\circ}, 4^{\circ}$ e $7^{\circ}$ ).

Em caso de rejeição tácita, ainda que a EC n. 32/01 tenha vedado a possibilidade de reedição de uma Medida Provisória, pode-se admitir a reedição de uma medida que tenha sido rejeitada pelo decurso do prazo dos 60 dias prorrogados por outros 60 dias.

Poderá também o Congresso Nacional, expressamente rejeitar a Medida Provisória e deixar de convertê-la em lei. Neste caso, assim como na rejeição tácita, deve o Congresso Nacional regular todas as relações jurídicas constituídas no período de vigência da Medida Provisória, através de decreto legislativo.

\subsection{A UTILIZAÇÃO DAS MEDIDAS PROVISÓRIAS NA ATUALIDADE}

Visto todo o arcabouço histórico que culminou na justificativa da necessidade de existência e aplicação do instituto que permite ao Poder

\footnotetext{
${ }^{25}$ MORAES, Alexandre de. Direito Constitucional, 33ª Ed., São Paulo: Atlas, 2017, p. 493.
} 
Executivo a edição de atos legiferantes, e visto quais os processos técnicos para que sejam utilizados no Brasil, deve-se questionar se vêm sendo utilizados de maneira correta e/ou efetiva pelos representantes políticos do país.

Desde a redemocratização, até o fim de 2018, o Poder Executivo brasileiro foi chefiado por sete diferentes Presidentes. Foram 30 (trinta) anos, ou 360 (trezentos e sessenta) meses da vigência do instituto das Medidas Provisórias, e, foram editadas neste período nada menos que 1.486 (mil quatrocentos e oitenta e seis) atos provisórios, legiferantes de prerrogativa do Poder Executivo com força de lei. ${ }^{26}$

Lembra-se que este instituto é resguardado para casos de extrema relevância pública ou urgência. A média nestes trinta anos, é de que foram editadas 1 (uma) Medida Provisória a cada 7 (sete) dias.

O Presidente da República que mais utilizou do instituto foi Luiz Inácio Lula da Silva (2003-2010), que editou a quantia de 419 (quatrocentos e dezenove) Medidas Provisórias no total de 96 (noventa e seis) meses de mandato. Porém, proporcionalmente, até o final do ano de 2018 o Presidente que mais utilizou do instituto, foi Itamar Franco, que em 27 (vinte e sete) meses editou nada menos que 142 (cento e quarenta e duas) Medidas Provisórias. ${ }^{27}$

$\mathrm{Na}$ teoria, seria dinamicamente funcional todo o processo de apreciação e validação das Medidas Provisórias. O Presidente da República a editaria, e, imediatamente, o Congresso Nacional, através de uma Comissão Especial Mista, seria convocado para apreciar se haveria necessidade e se os requisitos de urgência e relevância pública estariam sendo preenchidos.

Mas o corriqueiro é que desde a redemocratização existe o constate abuso do instituto, o que, em determinados momentos, causou uma parcial usurpação de funções entre o chefe do Poder Executivo e o Poder Legislativo e suas prerrogativas legiferantes.

Muitas matérias que são propostas através de Medidas Provisórias e são convertidas em lei, não observam os requisitos constitucionais, e poderiam (deveriam) serem apreciadas e tramitadas como um Projeto de Lei.

\footnotetext{
${ }^{26}$ Disponível em $<$ https://www2.camara.leg.br/atividade-legislativa/legislacao/mpemdia $>$. Acesso em 22 ago 2019.

${ }^{27}$ Disponível em <https://www2.camara.leg.br/atividade-legislativa/legislacao/mpemdia $>$. Acesso em 22 ago 2019.
} 
Como exemplos recentes, a Medida Provisória $\mathrm{n}^{\circ}$ 818, de 11 de janeiro de 2018, foi convertida na Lei ${ }^{\circ} 13.683$, de 19 de junho de 2018. A sua edição, altera a Lei ${ }^{\circ} 13.089$, de 12 de janeiro de 2015 (Estatuto da Metrópole) e a Lei ${ }^{\circ}$ 12.587, de 3 de janeiro de 2012 (diretrizes da Política Nacional de Mobilidade Urbana). Os efeitos dessa Medida Provisória foram mínimos, alterando algumas regras e definições contidas no dispositivo, e altera o prazo de elaboração do Plano de Desenvolvimento Urbano Integrado (PDUI).

Vê-se que a Medida Provisória não compreende urgência alguma, além de dilatar um prazo que já deveria ter sido cumprido pelo Poder Executivo, e todas as modificações trazidas por esta, deveriam ter sido realizadas através da iniciativa do próprio Legislativo.

\subsection{O IMPACTO DE INSEGURANÇA JURÍDICA COM A EDIÇÃO DE UMA MEDIDA PROVISÓRIA}

Um clássico exemplo da insegurança jurídica que se pode obter como resultado de uma Medida Provisória mal sucedida é a chamada "MP dos bingos"28 (Medida Provisória ${ }^{\circ}$ 168, de 20 de fevereiro de 2004).

Esta Medida Provisória proibia, em todo o território nacional, a exploração de todas as modalidades de jogos, à época, chamados de bingos, que compreendiam jogos em máquinas eletrônicas "caça-níqueis" e jogos de azar. As "casas de bingo", era como eram chamados os estabelecimentos destinados a prática de jogos de azar, uma espécie de cassinos.

Em seu texto, a Medida Provisória previa no art. $4^{\circ}{ }^{29}$, que o descumprimento do disposto no ato provisória, implicaria na aplicação de multa diária no valor de $\mathrm{R} \$ 50.000,00$ (cinquenta mil reais) para as casas de bingo que continuassem funcionando.

Desta forma, a decisão do Chefe do Poder Executivo, no mesmo momento em que editou a Medida Provisória n ${ }^{\circ}$ 168/2004, resultou em uma demissão em massa, estimada em cerca de 100.000 (cem mil) pessoas

\footnotetext{
${ }^{28}$ A Medida Provisória n ${ }^{\circ}$ 168/2004, foi editada pelo então Presidente da República, Luís Inácio Lula da Silva, com a intenção de proibir a exploração de diversas modalidades de jogos de azar que funcionavam em locais denominados "Casas de Bingo". A polêmica é proveniente da forma impositiva que foi editada a Medida Provisória, sem calcular os impactos financeiros e empregatícios que poderia gerar.

${ }^{29}$ MP 168/2004, Art. 4: "O descumprimento do disposto no art. $1^{\circ}$ desta Medida Provisória implica a aplicação de multa diária no valor de $\mathrm{R} \$ 50.000,00$ (cinquenta mil reais), sem prejuízo da aplicação de medidas penais cabíveis.
} 
que trabalhavam em casas de bingo em toda a extensão do território nacional.

Veja-se o poder que se concentra na edição de um ato normativo, unilateral, e com imediata eficácia com força de lei pode ter. Literalmente, da noite para o dia, a Medida extinguiu cerca de cem mil vínculos empregatícios, além de forçar a aplicação de medidas penais cabíveis, caso as multas diárias de alto valor não fossem o suficiente para interromper o funcionamento de alguma casa de bingo.

Desta forma, até a apreciação da Medida Provisória pelas Casas Legislativas, mantiveram-se as casas de bingo fechadas, e todos os funcionários delas desempregados, aguardando um desfecho pelo Poder Legislativo.

Em meados de maio do mesmo ano de 2004, em votação no Senado, ao apreciarem os pré-requisitos de urgência, além da constitucionalidade da mesma, foram registrados 31 votos a favor da Medida Provisória, e 32 votos contra. Assim, a Medida Provisória rejeitada e arquivada pelo então presidente do Senado Federal, José Sarney.

Diante da rejeição da Medida, pouco mais de 2 meses após sua edição, todos os cerca de cem mil funcionários e donos das casas de bingo puderam retornar às suas atividades, pelo menos naquele contexto.

Os reflexos e conflitos provenientes de toda essa situação, tiveram, ainda, de serem administrados e senados através de Decreto Legislativo, conforme institui nossa Carta Constitucional acerca de situações de rejeição expressa de Medidas Provisórias.

Dentro deste exemplo, pode-se extrair duas situações que demonstram o funcionamento deste instituto dentro de nosso sistema presidencialista, que é a inobservância dos requisitos constitucionais de urgência, em situação que não possa esperar o trâmite regular de uma lei ordinária, e a grande insegurança e impacto que pode uma lei sob condição resolutiva, pode causar.

\section{CONSIDERAÇÕES FINAIS}

A Atividade Legislativa exercida pelo Poder Executivo é, em determinadas democracias, fato funcional e fundamental para a garantia de uma atuação célere do Poder Público em situações que assim demandam. $\mathrm{O}$ instituto que permite esta atividade legiferante atípica, que sai do eixo do checks and balances, é extremamente útil para sanar entraves e etapas 
burocráticas do Poder Legislativo, que em praticamente uma unanimidade no mundo, é um Poder naturalmente mais complexo, cuidadoso e consequentemente moroso.

Ainda que seja algo que saia do consagrado princípio de Montesquieu, que influenciou praticamente todas as democracias ao redor do mundo, mostrou-se ser um instituto que vai além de sua utilidade, passa a ser necessário.

Mas ao mesmo que tempo que se verifica como um instituto que deva necessariamente estar acostado a qualquer Carta Constitucional, este deve ser compatível com o sistema de governo ao qual esteja inserido. Tão quão é necessária a existência do instituto, é fundamental a clareza das regras e requisitos que o permitam e o limitem, em ocorrências de abuso.

Na realidade brasileira, as Medidas Provisórias se mostraram um instituto historicamente necessário e que dificilmente será abandonado algum dia. Porém, mostrou-se ser, também, um instrumento poderoso para se conseguir "pular" as etapas de análise do Poder Legislativo ou, até, servir como um pilar para a construção de uma coalizão que permita o Executivo de atuar com menos interferência do Legislativo.

Além disso, o instrumento legiferante brasileiro é constantemente utilizado em descompasso com as normas Constitucionais, desrespeitando os requisitos objetivos de necessidade, urgência e relevância, resultando, assim, em recorrentes Medidas Provisórias sobre assuntos que não deveriam ser objeto da mesma.

Vê-se que o enorme número de Medidas Provisórias que foram editadas nos últimos 30 anos mostram claramente o descompromisso com as regras Constitucionais, além de causar uma enorme instabilidade jurídica, criando normas sob condição resolutiva que podem se desfazer em 120 dias, bem como sufocar as Casas Legislativas do Congresso Nacional com seu regime de urgência e obstrução de pauta.

Tão impactante é isto que ainda com o advento da Emenda Constitucional $n^{\circ} 32 / 2001$ que vedou a possibilidade de uma Medida Provisória ser reeditada numa mesma sessão legislativa, e com a interpretação que diminui as hipóteses de obstrução de pauta dada pelo Presidente da Câmara dos Deputados e posteriormente convalidada pelo Supremo Tribunal Federal, continuam impactando o Processo Legislativo a liquidez de relações jurídicas provenientes dos atos provisórias de maneira ainda considerável.

Vê-se que mesmo que seja um instrumento praticamente indispensável à administração e ao Poder público, devem, ainda, as 
Medidas Provisórias serem regulamentadas, de forma que dificulte a usurpação de sua real função que é editar atos normativos com força de lei em casos extremos de urgência.

Deve-se anotar algumas considerações de que as Medidas Provisórias foram importadas da Constituição Italiana, e de que os constituintes brasileiros construíram e instruíram tal instituto, tendo a plena convicção de que o sistema de governo em que vigoraria seria o Parlamentarismo, assim como é na Itália.

As Medidas Provisórias são notoriamente um instituto que tem seu funcionamento muito mais compatível com o parlamentarismo, pois sua rejeição resultaria automaticamente em uma moção de desconfiança ${ }^{30}$, refletindo como uma grande responsabilidade política que recairia sobre o Chefe do Executivo que, assim, teria muito mais cautela ao utilizar-se do instituto. Porém, no caso do presidencialismo brasileiro, essa responsabilidade política é inexistente, podendo o Presidente editar Medidas Provisórias sem qualquer responsabilidade acostada aos seus atos, além de transferir o dever de administrar os impactos provenientes de relações jurídicas criadas ou extinguidas pela Medida Provisória, ao Poder Legislativo, que deve regulamentá-las através de Decreto Legislativo.

As Medidas Provisórias são um instrumento fundamental para socorrer as demandas urgentes da sociedade, porém, visto a constante utilização sem responsabilidade e descompassada com os requisitos Constitucionais, o que se destaca é a falta de normas que limitem o seu uso, ou, uma incompatibilidade com o sistema Presidencialista. Talvez ambos.

\section{REFERÊNCIAS}

BRASIL. Constituição da República Federativa do Brasil de 1967. . Constituição da República Federativa do Brasil de 1988.

COSTA, Nelson Nery. Ciência Política, 2a ed., Editora Forense: Rio de Janeiro, 2006.

\footnotetext{
${ }^{30}$ Trata-se a Moção de Desconfiança, de um instrumento utilizados em sistemas Parlamentaristas, na forma de um manifesto apresentado por um grupo de parlamentares à sua própria câmara Legislativa, demonstrando seu descontentamento para com a política exercida pelo gabinete, com a finalidade de substituí-lo ou derrubá-lo. Em regra, caso acolhida a Moção, deve o chefe do Poder Executivo (gabinete) apresentar sua carta de demissão.
} 
ESPANHA. Constituição Espanhola de 1978. Disponível em:

<www.tribunalconstitucional.es/es/tribunal/normativa/Normativa/CEportugu\%C3\%A9s.pdf >. Acesso em 29 jul. 2019.

ITÁLIA. Constituição da República Italiana de 1947.

LENZA, Pedro. Direito Constitucional Esquematizado. Saraiva: São Paulo, 2016, p. 595.

MENDES, Gilmar Ferreira; COELHO, Inocêncio Mártires; BRANCO, Paulo Gustavo Gonet. Curso de Direito Constitucional, $6^{\text {a }}$ Ed., São Paulo: Saraiva, 2011.

MONTESQUIEU. Do Espírito das Leis. Martins Fontes: São Paulo, 2000.

MORAES, Alexandre de. Direito Constitucional, 33ª Ed., São Paulo: Atlas, 2017, p. 493.

SAMPAIO, Marco Aurélio. A Medida Provisória no Presidencialismo Brasileiro, $1^{\text {a }}$ Ed., São Paulo: Malheiros, 2007.

SANTOS, Brasiliano Pereira dos. As Medidas Provisórias no Direito Comparado e no Brasil, $1^{\text {a }}$ Ed., São Paulo: LTR, 1994, p. 286.

SUZUKI, Anderson; DIAS, Fábio Marques; VIOLIN, Marco Antônio. Medidas Provisórias e Segurança Jurídica, 1ª Ed., São Paulo: Juarez de Oliveira, 2003, p. 17.

TAVARES, André Ramos. Curso de direito constitucional positivo, Editora Saraiva: São Paulo, 2006. 